\title{
Multilinguales
}

\section{Cultures en conflit et rite de passage dans le sommeil du juste de Mouloud Mammeri}

cultures in conflict and rite of passage in le sommeil du juste of Mouloud Mammeri

\section{Dalil Slahdji}

\section{OpenEdition}

\section{Journals}

Édition électronique

URL : http://journals.openedition.org/multilinguales/1614

DOI : 10.4000 /multilinguales. 1614

ISSN : 2335-1853

\section{Éditeur}

Université Abderrahmane Mira - Bejaia

\section{Édition imprimée}

Date de publication : 1 juin 2014

Pagination : 111-124

ISSN : 2335-1535

\section{Référence électronique}

Dalil Slahdji, «Cultures en conflit et rite de passage dans le sommeil du juste de Mouloud Mammeri », Multilinguales [En ligne], 3 | 2014, mis en ligne le 03 juin 2014, consulté le 17 septembre 2019. URL: http://journals.openedition.org/multilinguales/1614; DOI : 10.4000/multilinguales.1614

Ce document a été généré automatiquement le 17 septembre 2019

\section{(c) (†) $\ominus$}

Multilinguales est mise à disposition selon les termes de la Licence Creative Commons Attribution -

Pas d'Utilisation Commerciale - Pas de Modification 4.0 International 


\title{
Cultures en conflit et rite de passage dans le sommeil du juste de Mouloud Mammeri
}

\author{
Cultures in conflict and rite of passage in le sommeil du juste of Mouloud
}

Mammeri

Dalil Slahdji

1 Nombreux sont les romans maghrébins d'expression française publiés dans les années 1950 qui rendent compte des rapports conflictuels entre les autochtones et les européens en période de colonisation. Il en est ainsi du roman de Mouloud Mammeri, Le Sommeil du juste, publié en 1955 aux éditions Plon. Nous nous proposons de démontrer que, dans ce roman, les oppositions culturelles mises en scène sont certes source de désillusion et de déception pour le personnage principal, mais nous pensons qu'il est également question dans le roman de la thèse de l'impossible communication entre les deux cultures (kabyle et française) et partant, de leur impossible conciliation, lisible notamment dans l'itinéraire d'Arezki, le personnage le plus important du roman (sans être le personnage principal).

2 Cette impossibilité à coexister se donne à lire dans l'itinéraire d'Arezki qui signe son retour au village par dépit.

3 En effet, dans Le sommeil du juste, qui se déroule pendant et peu après la seconde guerre mondiale, l'antagonisme entre les deux communautés est évident. La société kabyle, aux us et coutumes ancestraux, se heurte à la l'(in)justice coloniale, qui la dénigre en remettant en cause ses codes séculaires. C'est ce qui donne au roman le ton dominant de la déception et de l'impuissance. Le père est dessaisi de ses repères parce que, par la volonté toute puissante du Komisar qui ne lui laisse aucune chance de réagir, ses valeurs et ses certitudes sont reniées; le jeune fils sliman finit par comprendre que l'espoir né de la guerre ne changera ni son sort ni celui de sa communauté ; le fils cadet Arezki, l'élève de l'Ecole normale, est plus que déçu de se rendre compte du hiatus entre la réalité coloniale et les valeurs humanistes qu'on lui a inculquées à l'école et 
auxquelles il a cru; le fils aîné Mohand, parti en France pour gagner sa vie, la perd en quelque sorte puisqu'il revient malade et plein de rancoeur parce qu'il sait sa mort proche.

4 Partant de ce constat, nous tenterons de démontrer, à la lumière de ce que nous enseigne l'ethnocritique, que dans Le Sommeil du juste, il n'y a pas une simple revendication identitaire du fait culturel kabyle et, par voie de conséquence, une revendication de l'algérianité en période de colonisation comme le suggèrent beaucoup d'études ${ }^{2}$. Nous pensons que le texte de Mouloud Mammeri illustre davantage la thèse de l'impossibilité pour les deux cultures de trouver un espace de cohabitation; thèse portée essentiellement (mais pas exclusivement) par Arezki, qui, par son parcours, est l'incarnation de cette tentative en tant qu'elle est vouée à l'échec.

\section{La désocialisation d'Arezki ou le rite de passage inversé}

5 A travers les différents épisodes qui ont jalonné la vie d'Arezki, l'idée peut être émise que l'auteur a mis en place un scénario que nous envisageons comme un rite de passage inversé car tout en en respectant les étapes, il aboutit à la désillusion et à la désocialisation du sujet au lieu de sa socialisation. C'est la conséquence de l'apprentissage reçu à l'école coloniale. Le savoir ainsi acquis est à l'origine de sa marginalisation. En effet, l'enseignement de l'école française engendre sa double exclusion, de la société occidentale et de sa propre communauté.

6 Pour le démontrer, nous exploiterons la structure ternaire du rite de passage selon la conception de Van Gennep Arnold (1909)3 : une "phase de séparation" (ou préliminaire) du groupe, suivie d'une "phase de marge » (ou liminaire) qui débouche sur une " phase d'agrégation » (ou postliminaire).

7 En retraçant l'itinéraire d'Arezki, on constate qu'il passe effectivement par les trois phases dont chacune marque en lui l'irruption d'un certain désordre dans le continuum de son existence.

8 La première phase, ou phase de séparation se situe au début du roman. Arezki va quitter son village parce qu' ' il n'y avait pas d'école à Ighzer naturellement, mais il y en avait une dans le lointain village de Tasga où on avait envoyé Arezki chez une sœur de sa mère» (11). L'entrée à l'école de Tasga, ce "village lointain", est vécue par Arezki comme une " séparation ", même si le lien avec son village et sa famille n'est pas rompu : Arezki « revenait pour les vacances » (11).

9 Il n'en demeure pas moins qu'il s'agit bien d'une séparation pour les parents qui voulaient se «débarrasser de cette petite fille qui ne servait à rien » (11), et pour Arezki : " Quand j'ai quitté pour la première fois Ighzer pour le vaste monde (le vaste monde c'était l'école primaire supérieure de Tizi Ouzou), je me souviens, la joie riait dans l'air clair et froid d'octobre $»(90)$.

10 Cette séparation est d'autant plus effective chez Arezki qu'il est en déphasage par rapport à la vie communautaire :

«Comme il ne savait rien faire on ne lui demandait rien. Il faut dire qu'il était peu encombrant: on le déplaçait comme un meuble. Si quelqu'un avait besoin de la place où Arezki s'était par hasard assis il n'avait qu'à le toucher à l'épaule. Il était poli, disait toujours oui à tout. Il n'était pas fier malgré ses mains blanches 
d'homme qui n'a jamais eu à racler sur les cailloux la faucille ou le mancheron, ses paumes bleutées de veines opalines. » (12) l'enseignement reçu à l'école coloniale, et endoctriné par son maître, il se moque ouvertement des valeurs de sa communauté : «L'honneur c'est une plaisanterie. [...] Je me moque du diable et de Dieu. [...] Non, mais j'ai lu dans les livres. [...] Que Dieu n'existait pas » (8-10).

Séparé des siens, Arezki embrasse totalement la culture occidentale, telle que professée par les maîtres et les livres, en lui faisant allégeance. C'est à l'insignifiance de la vie à Ighzer qu'Arezki veut échapper car il ne souhaite pas quitter le monde « sans avoir joué le plus petit bout de rôle » (79-80). Au nom de l'enseignement qu'il a reçu, il condamne sa culture à une révocation sans appel :

" "Mort au monde? mais c'est vous qui l'êtes. Je sais, moi, des choses dont votre sagesse ne se doute même pas : j'ai lu les livres, un monceau, et, si dans la masse des livres que j'ai lus, ni Ighzer ni Hand ni votre misère ne sont cités, ce n'est pas malédiction, c'est justice : vous n'en valiez pas la peine. (...) Votre sagesse fossile, votre monde, votre pauvre petit monde, si vous saviez comme je m'en moque. Oh, là, là, si vous saviez!" Détruire, couper, pourfendre, renverser, je voulais tout renverser. » (93) 
Arezki était devenu anarchiste comme son instituteur et il justifie le rejet de sa communauté par son absence dans ce qu'il a appris à considérer comme le lieu de la légitimité culturelle :

« Rien. Personne. Ils n'étaient cités nulle part. Ils n'avaient pas existé. (...) Pourquoi Hand si éloquent n'avait-il rien laissé dans le bon berbère d'Ighzer que lui Arezki, connaissait si bien? (...) Les livres succédaient aux livres, mais c'était Newton qui changeait le monde en regardant tomber une pomme, Socrate qui mourait en buvant la ciguë (...). Quand il eut tout lu, il prit de la poche de sa vareuse le cahier bleu et écrivit : "Imann, mes frères, il n'y a nulle trace de vous dans tout ceci. Vous êtes morts, bien morts, si morts qu'il faudrait pour vous tirer de la tombe une force plus qu'humaine. Lazare n'a ressuscité qu'à la voix d'un prophète...et je ne suis pas de taille, vous le comprendrez aisément". » (95)

19 Arezki accède donc à un monde où il n'y a nulle trace des siens et ce manque de reconnaissance est assimilé à la mort.

Son entrée dans cet univers, impliquant sa séparation avec les siens, est la seconde phase du rite : la phase liminaire caractérisée par une initiation en marge du groupe.

Son initiation se fait dans la douleur:

«Longtemps les cours que je suivais de toutes mes oreilles restèrent pour moi incantations mortes d'une tribu étrangère. Rien dans le monde nouveau et jadis désiré où j'entrais n'était fait pour moi. Dès le premier soir j'avais été pour mes camarades l'ennemi, longtemps pour tout le monde je restai l'étranger. J'errai dans un monde hostile ou indifférent. Les efforts que je fis pour échapper à cette condition nul ne les a soupçonnés, pas même vous dont j'ai été le disciple aimé. Il fallait chaque jour m'arracher à un peu de ce qui avait été moi ; je ne croyais pas que ce dût être si douloureux. (...) Le soir au dortoir dès que le surveillant avait éteint, j'enfonçais ma tête dans les couvertures et je pleurais de n'avoir pas compris la moitié de ce que le professeur de français avait dit. » (90)

22 Malgré ses "efforts", son initiation ne permet pas sa pleine intégration dans sa nouvelle communauté. Il restera inscrit malgré lui dans la marge. Cette phase de marge se prolongera jusqu'à sa mobilisation durant la seconde guerre mondiale. A la fin de la guerre, il se retrouve à Paris, errant dans les rues, irrésolu.

23 A ce stade de son parcours, la marginalisation d'Arezki s'accentue pour se transformer en désocialisation. Confronté à plusieurs épreuves dégradantes (racisme, humiliation, vexations, etc.), le jeune aspirant Arezki prend enfin conscience qu'il est lui aussi, comme ses siens, Imann rejeté par la société française. S'être battu pour la France, avoir obtenu des galons ne lui évitent pas d'être servi au réfectoire après les officiers européens moins gradés que lui, contrairement au règlement, d'avoir une solde inférieure à celle des autres collègues européens de même rang, d'être obligé d'obéir à un autre officier de même grade que lui. Son initiation ne l'a pas sauvé de son statut initial, imann, qu'il partage avec ceux dont pourtant il s'est séparé.

C'est en tant que militaire qu'il commence, en effet, à prendre vraiment conscience des injustices auxquelles son instruction ne l'avait pas préparé malgré son ampleur: «Ce que j'ai avalé de siècles, d'auteurs, de mots, de raisonnements, mieux que quiconque vous me l'avez appris. Mon orgueil rentré croissait avec une science que je croyais infaillible, sans borne » (91).

25 Pourtant, il a manifesté de la ferveur à partir à la guerre pour défendre les idéaux auxquels son maître l'avait initié : "Je vous promets, mon cher maître, que je m'y battrai sans faiblir pour le triomphe d'une cause que je sais être, malgré vous, la vôtre» (83). Mais, 
Arezki connaît la désillusion et perd peu à peu confiance dans les valeurs d'humanisme de l'occident qui lui ont été inculquées.

C'est ainsi qu'il décide de brûler tous les livres auxquels il a cru :

«Voici, dit Arezki, que l'heure du grand sacrifice est venue. (...) La flamme, brusquement grossie, (...). Lentement la flamme caressait les feuilles et doucement gagnait de proche en proche Molière, Shakespeare, Homère, Montesquieu (...). Quand le feu eut dévoré le dernier tome et qu'à l'endroit où tant de savoir avait été enfermé, tant de sagesse enclose, il ne resta plus qu'un petit tas de cendres que la brise faisait voler en minuscules papillons noirs, Arezki porta la main sous la ceinture de son pantalon. La patronne entra et (...) commença de vociférer :

- Allons, allons, messieurs...mais....qu'est-ce vous faites là?

- Je pisse sur les idées, dit Arezki. » (101-102)

Par cet acte, Arezki renie sa foi en l'humanisme et aux valeurs universelles de l'occident. A ce sujet, Malika Hadj Naceur écrit :

«En brûlant les dieux précédemment adorés (ses livres et les idées qu'ils véhiculaient) Arezki répudie sa foi dans l'humanisme européen et se prépare à retourner vers les siens, ayant enfin compris qu'on ne peut s'assumer que parmi eux et que les institutions traditionnelles qu'il dénigrait sont en fait un rempart contre l'aliénation culturelle et sociale. $»^{4}$

En effet, cet épisode signe sa prise de conscience et l'acte de décès de l'assimilation/ acculturation d'Arezki. Et l'ultime leçon d'humanisme du maître à ses disciples (Arezki et Meddour) semble déjà bien lointaine :

«Un homme digne de ce nom fait que la bête s'éveille mais ne se déchaîne pas. Il se doit d'être bestial avec lucidité, et dans le grand tumulte, derrière les cris de la bête, sait écouter la voix de l'ange. Je vous conseille donc de tenir de vos faits et gestes, voire de vos pensées, un registre précis, détaillé, sans complaisance. Ce journal sera au milieu de la barbarie déchaînée un refuge de conscience et d'humanité, au milieu des ténèbres la flamme qui veille, parce que l'homme ni la vérité ne peuvent périr. » (81)

Cette « leçon » du maitre, qui, auparavant leur aurait fait croire qu'elle les « haussait au niveau d'une humanité supérieure» (81), ne suscite plus l'enthousiasme. Avec lucidité, Arezki écrit à M. Poiré : « [...] j’ai par bonheur oublié tous ceux (les mots du maitres) qui ne servaient à rien : la moitié des vôtres y ont sombré » (117-118).

Pour lui, ces " mots ", au lieu de favoriser son intégration à la société occidentale, l'ont au contraire fragilisé parce qu'ils ne l'ont pas préparé à affronter le rejet et l'humiliation dont il sera l'objet. Arezki, en effet, dans son parcours butte violemment contre cette société française qui ne le reconnaît pas et il juge l'école française responsable de son malheur:

«Il me semble avoir été lâché dans la jungle, sans dents pour mordre, sans armes, pis, gêné d'intelligence, encombré d'innocence et de scrupules, quelque chose comme la victime rêvée, l'agneau du sacrifice. » (94)

31 Nous concluons donc à l'échec de la phase de mise en marge en tant que phase intermédiaire dont la finalité aurait dû être le passage au troisième stade du rite: l'agrégation.

Certes, Arezki revient au sein de sa famille, à la fin du roman : "Arezki entra dans la vie d'Ighzer comme un nageur se jette à l'eau : d'un coup » (143). Il semble désormais résigné puisqu'il a perdu la volonté de vouloir changer l'ordre des choses exprimée au début du roman : 
" Arezki sentit ses yeux se couvrir du voile de jadis et comme jadis il eut envie de cogner, de détruire, de briser, envie de crier à tous ces vieillards qu'ils n'étaient plus des Kabyles, plus des hommes, envie de les chasser tous à coups de bottes. Il se rappela Ricardo, Zerrouk, la gare de Lyon, les corps abandonnés de la rue de la Lyre. Il se rappela surtout le coup de fusil [...]. Il faillit ricaner comme jadis, se retint à temps. » (144)

Son initiation aura finalement fait de lui un être résigné et asocial. Son retour au village se fait par dépit. Il tente bien de compenser la perte de la foi en la parole du maître en intégrant «le parti » politique, mais sans grande conviction (124-125).

\section{Liminalite et identité culturelle}

La désocialisation d'Arezki pose la question de son identité culturelle dans la mesure où celle-ci est censée signer l'appartenance à un groupe culturel donné. Ayant rejeté les valeurs ancestrales de sa communauté et ayant été rejeté par la société française, Arezki se place dans un entre-deux culturel flou et indéterminé. De ce point de vue, il peut être assimilé à un personnage liminaire tel que le définit Marie Scarpa (2009) :

«Est liminaire un personnage bloqué dans un état intermédiaire au cours de son « initiation" (soit dans la construction de son identité individuelle, sexuelle et sociale). De ce point de vue, c'est un "inachevé", gardant de sa situation d'entredeux états une ambivalence constitutive. » (221)

Dans Le Sommeil du juste, Mouloud Mammeri thématise la marginalisation de son personnage dans le programme narratif de son récit et lui assigne une identité culturelle vacillante. Ainsi, Arezki est un personnage marginalisé dont l'itinéraire, balisé par une série de " décrochages » sociaux depuis l'enfance, lui confère un statut à la fois de non-initié et de sur-initié tel que défini en ethnocritique :

«Certains personnages (...) ne "passent " pas, ne franchissent pas (ou mal) les seuils et les étapes inhérents à la construction individuelle et sociale de l'identité. Non initiés ou mal initiés - hommes ou femmes "inachevés" culturellement -, ils restent bloqués dans un entre-deux constitutif. Leur ambivalence structurelle (ils ne sont plus ce qu'ils étaient et ne seront jamais ce qu'ils auraient dû être) fait trembler les lignes de partage sur lesquelles se fondent la cosmologie d'un groupe social et qui se jouent précisément dans les espaces-temps de la marge où s'explorent les limites entre les vivants et les morts, le masculin et le féminin, le civilisé et le sauvage.» (Scarpa, $2013 \mathrm{c}:$ 16-17)

L'ambivalence structurelle que supporte Arezki est la conséquence de son apprentissage de la culture occidentale qui l'éloigne de sa famille et de sa culture d'origine lesquelles, au nom du nouveau savoir acquis sont dénigrés. Mais, paradoxalement, ce même savoir devient un obstacle qui ne lui permet ni une intégration de la société française, ni une réintégration à sa société d'origine. Le personnage se désocialise du monde. Il sera définitivement inscrit dans la marge incarnée par la prison où il finit enfermé pour un crime qu'il n'a pas commis.

Arezki est donc un personnage liminaire dont l'identité culturelle est problématique. Celle-ci, inscrite dans le double rejet, a du mal à se construire puisque Arezki tourne le dos à sa communauté, à sa famille et la société française lui tourne le dos. Il n'appartient ni à l'une, ni à l'autre. Son identité reste coincée entre deux cultures, d'où sa position liminaire entre " les vivants et les morts », autrement dit « en prison ». 

que vit le personnage principal depuis le début du roman. En effet, l'auteur distille le long de son texte des éléments pour représenter Arezki qui le définissent inexorablement dans la marginalité et la liminalité.

exfet, dès son enfance et pour qualifier son existence, Arezki écrit dans une lettre à son maître, M. Poiré: "Il me semble discerner dans le temps les premiers signes du malentendu dont je subis malgré moi les conséquences. Le malentendu a commencé pour moi dès ma première enfance» (89-90). A cet aveu d'impuissance et à ce malentendu de son existence s'ajoutent des motifs de la marginalité. Rappelons qu'il est le cadet de sa fratrie, position intermédiaire entre Mohand, l'aîné, et Sliman, le benjamin. Jeune, sa ressemblance péjorative à une fillette, représentée dans la société kabyle comme un être fragile, est soulignée à maintes reprises :

«(...) On avait envoyé Arezki chez une vieille sœur de sa mère pour se débarrasser de cette petite fille qui ne servait à rien et qui, quand on lui confiait quatre ou cinq brebis à faire paître, revenait les yeux rouges d'avoir pleuré.» (11)

t même adulte, à la fin du roman, le gardien de prison évoquera ses «joues roses ». Ce « handicap » dont est affublé Arezki est accentué quand Elfried, la femme aimée et dont pourtant il se sépare, le qualifie d'ange, que lui-même s'y identifie et que l'auteur lui consacre un chapitre entier intitulé L'Ange (79-142).

41 La question se pose de savoir pourquoi le choix d'un tel personnage, être asexué, intermédiaire entre l'humain et le divin ? Mouloud Mammeri déclare à ce sujet :

«J'ai dans chacun de mes romans défini une espèce de point de référence, de centre auxquels se rapportent tous les événements. Ce personnage qui sert de référent a pour caractéristique, pour nature, en quelque sorte de voir avec lucidité les événements tels qu'ils sont et surtout d'être exigeant (...). C'est la raison pour laquelle chaque fois j'ai choisi un intellectuel. Parce qu'il est plus facile à un intellectuel de conceptualiser le destin humain. $»^{5}$

Conceptualiser le destin humain, voilà donc le rôle assigné à Arezki, comprendre et donc, en quelque sorte, concilier les deux sociétés (occidentale et kabyle). Mais, c'est au prix d'une violente marginalisation qu'il accomplit cette tâche, car il restera entre les deux mondes, dans un no man's land. Sa mission de passant ou de médiateur entre les deux cultures est un échec car impossible. Il ne sera que la victime de son acculturation et le témoin impuissant du « malentendu » (170) entre les deux sociétés.

Enfin, l'exclusion et la liminalité d'Arezki, se manifestent également dans les propos de certains personnages. Ainsi, pour Sliman, son frère, il est un Aroumi (51), un étranger (129); pour Lounas, le compagnon en lutte contre la société coloniale, il est un égaré (53) ; Arezki ne sera pas le gardien officiel de la tradition car l'amin ${ }^{6}$ a choisi son jeune frère Sliman pour prendre la place de Mohand, après sa mort, auprès de son épouse Mekioussa, alors que la coutume le désignait. Il n'épousera pas non plus Elfriede connue durant la guerre. Arezki, n'établira, par conséquent, de lien social ni avec la société kabyle ni avec la société française. Son initiation l'a « arrach(é) à un peu de ce qui avait été (lui) ", sans faire de lui quelqu'un d'autre, mais suffisamment effective pour rendre sa réinsertion dans son monde initial. Son père assimile sa position à la mort :

«Tu n'as pas d'amis pour te réjouir avec eux, pas d'ennemis à haïr, tu es mort aux choses et les choses mortes à toi. Tu traverses tout comme un étranger...comme le mendiant hagard dont un voile couvre les yeux ouverts mais aveugles. Alors pourquoi tes yeux brûlent-ils? (...) Un jour tu reviendras, si tu continues à revenir encore; et tu seras loin, si loin que c'est à peine si on reconnaîtra à l'horizon tes 
traits flous, et puis même cette vague silhouette de toi fondra dans le ciel... là-bas...

dans le bleu...personne ne te pleurera, mais tu seras mort tout de même. » (92)

Le père confirme ainsi qu'Arezki est à la « limite entre les vivants et les morts ", stade liminal que le roman donne à lire comme celui d'un personnage d'un mort parmi les vivants, "prisonnier» pour l'éternité (fictive). Certes, ce statut de «mort-vivant» d'Arezki, qui a rejoint la France avant de revenir dépité, diffère de celui de son frère Mohand qui a, lui aussi rejoint la France, mais pour y travailler avant de revenir, lui aussi dépité, pour attendre la mort parce qu'il a contracté la tuberculose à l'usine.

Mais que ce soit pour le premier, qui a eu foi en la société française au détriment de la sienne, ou pour le second, dont les motivations étaient alimentaires, le contact avec la société française s'avère funeste.

Nous pouvons conclure que le roman de Mammeri, en thématisant le conflit culturel que nous évoquions plus haut, repose sur la thèse de l'impossible rapprochement des deux communautés, quelle que soit la modalité d'approche du protagoniste : le bon sens du père échoue devant le Komisar, la neutralité de Mohand vis-à-vis des deux sociétés avant sa maladie et son retour, et la tentative d'assimilation d'Arezki.

7 La barrière entre les deux sociétés est insurmontable: d'un côté une société kabyle archaïque, qui oblige le jeune slimane à épouser sa belle-sœur alors qu'il est amoureux d'une autre, obligée elle-même à en épouser un autre ; de l'autre, une société française qui, dans ses actes, s'inscrit en faux contre ses discours humanistes.

4 Le sommeil du juste raconte le destin funeste de ceux, comme Arezki, Mohand, ou le père, ont eu affaire à elle: Arezki est victime de l'école française, de ses livres et de son instituteur ; Mohand, des usines Renault ; le père, de l'administration coloniale.

Comme le suggère le roman, ce sort historique funeste des personnages, inscrit explicitement la colonisation dans la malédiction séculaire qui frappe la famille et le village. Cette inscription de l'historique dans la logique maléfique explique la fin du roman : le meurtre du cousin Toudert, à la fois ennemi «maudit » du clan et allié de l'administration coloniale contre les gens du village. Il devait payer sa dette, celle du sang, contractée par son aïeul, et celle de l'histoire, qu'il a contractée lui-même en vendant les siens à l'ennemi.

\section{BIBLIOGRAPHIE}

ABBES-KARA Y.A, « Métissage linguistique et culturel dans l'œuvre romanesque de l'écrivain Algérien francophone : Mouloud Mammeri ", in C. Condei, J.-L. Dufays et C. N. Teodorescu (Eds), Métissage culturel. Effets de la mondialisation chez les écrivains francophones, Craiova, éd. Universitaires, 2009, pp. 87-106.

ARON P, SAINT-JACQUES D., VIALA A., Le dictionnaire du littéraire, Paris, PUF, 2002.

DJAOUT T, Entretien avec Tahar Djaout, Alger, éd. Laphomic, 1987. LANASRI A., La littérature

algérienne de l'entre-deux-guerres. Genèse et fonctionnement, Publisud, 1995. 
MAMMERI M., Le Sommeil du juste, El Dar El Othmania, 2005 (1re ed. 1955). KEBBAS M, KASSOUL A, MAOUGAL M.L, MOULOUD MAMMERI, Casbah édition, Alger, 2008.

SCARPA M., L'Eternelle jeune fille. Une ethnocritique du Rêve de Zola, Edition Honoré Champion, 2009 a.

SCARPA M., « Le personnage liminaire », ROMANTISME, n 145, 2009 b, pp. 25-35. URL : www.cairn.info/revue-romantisme-2009-3-page-25.htm SCARPA M., « L'ethnocritique de la littérature présentation et situation », in Multilinguales, $n^{\circ}$ 01, Université de Bejaia, 2013, pp. 7-18. Disponible sur le site : http://www.univ-jaia.dz/documents/multilinguales/ version\%20integrale.pdf

PRIVAT J-M., SCARPA M., « Présentation. La culture à l'œuvre », ROMANTISME, n 145, 2009, pp. 3-9. Consultable sur le site : www.cairn.info/revue-romantisme-2009-3-page-3.htm

VAN GENNEP A., Les rites de passage. Etude systématique des rites, Picard, 1981, (1re éd.1909).

\section{NOTES}

1. Le concept de "liminalité », emprunté par l'ethnocritique à l'anthropologie, est défini par Victor Turner dans son ouvrage The Ritualprocess (1969) en ce qu'il : «instaure un temps et un espace de coupure destinés à souligner la différence entre l'état antérieur et l'état postérieur. Cette coupure prend la forme d'une période de marge ou de "liminalité » au cours de laquelle les impétrants du rituel sont en situation marginale par rapport aux règles et obligations sociales "normales " ", cité dans Encyclopedia Universalis, à l'article « Rite de passage».

2. Voir à ce sujet les travaux publiés dans La littérature maghrébine de langue française, ouvrage collectif, sous la direction de Charles Bonn, Naget Khadda \& Abdallah Mdarhri- Alaoui, Paris, EDICEF-AUPELF, 1996.

3. Nous nous référons à la réédition de l'ouvrage aux éditions Picard, 1981, pp. 14- 27.

4. La littérature maghrébine de langue française, Ouvrage collectif, sous la direction de Charles Bonn, Naget Khadda \& Abdallah Mdarhri-Alaoui, Paris, EDICEF-AUPELF, 1996.

5. Mouloud Mammeri cité par Malika Kebbas, Aicha Kassoul, Maougal M. Lakhdar, DANS MOULOUD MAMMERI, op. cit.

6. Camille Lacoste-Dujardin définit l'amin comme le titre attribué à un chef de village, ou un président de la jemaâ (l'assemblée), élu parmi les hommes adultes. Il fait aussi office de maire du village : il administre les biens et les finances des habitants et assure l'ordre dans le village.

\section{RÉSUMÉS}

Dans le cadre de cet article, nous tenterons d'expliciter quelques aspects des enjeux culturels dans Le Sommeil du juste de Mouloud Mammeri (1955). Nous voulons démontrer que les contacts entre la culture kabyle et la culture française, pendant la colonisation de l'Algérie, sont source de conflits entre les deux communautés en présence, rendant leur rapprochement impossible. Pour étayer notre thèse, nous avons suivi l'évolution du personnage central, Arezki, dans un univers de la fiction construit sur le principe de l'inadéquation des valeurs de l'humanisme républicain, prôné dans les livres et par les maîtres de l'école française, avec la réalité coloniale. Cet 
antagonisme, qui prend en tenaille Arezki, est puissant au point de le pousser à sa «désocialisation» progressive. Nous avons parlé de rite de passage inversé : l'initiation aux valeurs occidentales, qui devaient aider Arezki à s'intégrer à la compréhension du monde et à son intégration, débouche sur une «identité liminaire ${ }^{1}$.

Our objective in this article is to clarify some aspects of the cultural issues included in Mouloud Mammeri's Le Sommeil du juste (1955) in order to demonstrate that interactions between the Kabyle culture and French culture during the colonization of Algeria generated conflicts between the two communities leading to an impossible rapprochement between them. For this purpose, we followed the evolution of the central character, Arezki, in a world of fiction built on the theory of the inadequacy of the values of republican humanism, advocated in the books and by the masters of the French school, with the colonial reality. We showed that this antagonism is strong enough to cause Arezki's progressive « désocialisation ».

\section{INDEX}

Mots-clés : Ethnocritique, culture, rite de passage, Mouloud Mammeri, Le Sommeil du juste Keywords : Ethnocritic, culture, rite of passage, Mouloud Mammeri, Le Sommeil du juste

\section{AUTEUR}

\section{DALIL SLAHDJI}

Université A. Mira-Bejaia - Laboratoire LAILEMM

SLAHDJI Dalil est enseignant au département de français de la faculté des lettres et des langues de l'Université Abderrahmane Mira - Bejaia. Il prépare une thèse en sciences des textes littéraires sur la « Poétique de l'opacité dans Lui, Le livre et Pays d'aucun mal d'El-Mahdi Acherchour, La camisole de gré de Farid Abache, et dans L'entre-deux vies de Bouabdellah Adda ». Il est membre de l'équipe de recherche « Lectures anthropologiques des textes maghrébins : nouveaux enjeux pour l'ethnocritique », du laboratoire de recherche-formation en langues appliquées et ingénierie des langues en milieu multilingue - LAILEMM.

Domaine de recherche :

Sciences des textes littéraires, littérature maghrébine francophone Publication :

« Lui, Le Livre d'El-Mahdi Acherchour ou la déconstruction du champ romanesque », in Synergies Algérie, $\mathrm{n}^{\circ}$ 13, Gerflint, 2011. 